\title{
Chemical and Dynamical Effects on Cloud Droplet Number: Implications for Estimates of the Aerosol Indirect Effect
}

SARA LANCE ${ }^{1}$ A. NENES ${ }^{1,2 *}$, T. RISSMAN ${ }^{3}$

${ }^{1}$ School of Earth and Atmospheric Sciences and ${ }^{2}$ School of Chemical and Biomolecular Engineering, Georgia Institute of Technology, Atlanta, GA

${ }^{3}$ Department of Chemical Engineering, California Institute of Technology, Pasadena, CA

Submitted to the Journal of Geophysical Research

* Corresponding author 


\begin{abstract}
Most aerosol-cloud-climate assessment studies use empirical aerosol-droplet number relationships, which are subject to large variability. Historically, this variability has been attributed to unresolved variations in updraft velocity. We revisit this postulation and assess the effects of both updraft velocity and chemical composition on this variability. In doing so, we utilize an inverse-modeling approach. Using a detailed numerical cloud parcel model and published aerosol characteristics, with published correlations of cloud droplet vs. sulfate and cloud droplet vs. aerosol number as constraints, we determine a most probable size distribution and updraft velocity for polluted and clean conditions of cloud formation. A sensitivity analysis is then performed to study the variation in cloud droplet number with changes in aerosol chemistry and updraft velocities. This addresses the need to estimate the importance of chemical effects on spatial scales relevant for global climate models.
\end{abstract}

Our analysis suggests that the effect of organic surfactants can introduce as much variability in cloud droplet number as that from expected variations in updraft velocity. In addition, the presence of organics seems to further enhance the sensitivity of droplet concentration to vertical velocity variability. The variability from organic surfactants is seen to be insensitive to variations in aerosol number concentration, implying that such effects can affect cloud droplet number consistently over large spatial scales. Our findings suggest that organics can be as important to the aerosol indirect effect as the effect of unresolved cloud dynamics, and illustrate the potential and complex role of chemical effects on aerosol-cloud interactions. 


\section{Introduction}

The largest uncertainty in prediction of anthropogenic influences on climate change involves the details of the hydrological cycle [Intergovernmental Panel on Climate Change (IPCC), 2001]. Water in the atmosphere has three major, competing effects on climate. Water vapor is the primary greenhouse gas in the Earth's atmosphere. Conversely, liquid water in the form of suspended cloud droplets accounts for about $30 \%$ of the Earth's albedo [Charlson et al., 1987]. Water ice in the upper troposphere absorbs infrared radiation emitted by the Earth. The mechanisms for distribution of each phase are therefore important for determining the overall effect of atmospheric water on climate. This study focuses on the formation of liquid water clouds.

Cloud droplets in the atmosphere are formed from condensation of water vapor upon cloud condensation nuclei (CCN). Both the physical and chemical characteristics of a CCN population influence the number and size of cloud droplets that form. However, the physical and chemical properties of $\mathrm{CCN}$ vary significantly with space and time, since the sources and sinks of $\mathrm{CCN}$ are localized and since $\mathrm{CCN}$ have short atmospheric lifetimes (as compared to the mixing timescale of the atmosphere). In addition, the cloud updraft velocity, which is highly variable within a cloud and difficult to measure [Mason, 1971], has a strong influence on the number and size of cloud droplets formed; a higher updraft provides a higher water-vapor supersaturation, which is the driving force for condensational growth. The wide variability in these parameters, to which cloud droplet formation is highly sensitive, causes much of the uncertainty in cloud modeling. 
Most of the radiative properties of liquid water clouds can be inferred from knowledge of the cloud liquid water content and cloud droplet number concentration. Twomey [1974] suggested that increasing the number of aerosol particles increases the number of $\mathrm{CCN}$, which increases the number of cloud droplets and leads to a higher cloud albedo. The increased cloud reflectivity, and the associated radiative cooling, is referred to as the "first indirect climate effect" of aerosols. Global Climate Models (GCMs) are currently incapable of providing the resolution necessary for explicitly addressing the scales involved in aerosol-cloud interactions; instead, empirical correlations between cloud droplet number and one aerosol characteristic (e.g. number concentration [Gultepe and Isaac, 1999] or sulfate mass [Boucher and Lohmann, 1995]) are often used to quantify aerosol-cloud interactions. The variability inherent in such relationships translates to a large predictive uncertainty of the indirect effect, potentially as large as the greenhouse gas radiative forcing [IPCC, 2001]. For example, in the Boucher and Lohmann [1995] observations, the cloud droplet number concentration ranges from 60 to $600 \mathrm{~cm}^{-3}$ for an aerosol non-sea-salt (nss) sulfate mass of $1 \mu \mathrm{g} \mathrm{m}^{-3}$. For the same liquid water path, this variability in cloud droplet concentration could lead to a change in cloud reflectivity of up to $\sim 60 \%$ [Seinfeld and Pandis, 1998]. This large variability shows that cloud droplet number is strongly influenced by factors other than sulfate mass, but does not indicate what the variability can be attributed to.

The variability in the Boucher and Lohmann [1995] and Gultepe and Isaac [1999] observations is historically attributed to variations in cloud updraft velocity [IPCC, 2001]. Although updraft variations may produce an order-of-magnitude range in droplet number, recent work has suggested that a variety of organic chemical effects, including 
reduction in surface tension and modified growth kinetics, can potentially contribute as much to the variability in cloud droplet number as updraft velocity.

Several studies have shown that organic compounds can reduce the surface tension of droplets. Facchini et al. [2000] observed a decrease of up to $25 \%$ in the surface tension of polluted fog water samples, as compared to the surface tension of water. The surface tension depression was shown to be a function of the bulk concentration of water-soluble organic compounds (WSOC) [Facchini et al, 1999]. Facchini et al [1999] estimated, using Köhler theory and assuming a power-law relationship between droplet number and supersaturation, that the maximum decrease in surface tension could lead to an $\sim 20 \%$ increase in the number of cloud droplets. Li et al [1998] found that laboratory-generated aerosol consisting of mixtures of sodium dodecyl sulfate (SDS) and $\mathrm{NaCl}$ can lower the surface tension by up to $20 \%$ compared to the same size dry particle composed of pure $\mathrm{NaCl}$. Shulman et al [1996] measured the solubility and surface tension of laboratory generated aerosols, which consisted of two-component mixtures of ammonium sulfate and various difunctional organic oxygenates that have significant concentrations in the atmosphere (e.g. cis-pinonic acid and glutaric acid). The observed surface tension decreased by as much as $20 \%$ compared to water. It was also found that higher concentrations of ammonium sulfate actually enhanced the surface tension depression for cis-pinonic acid. This relatively high molecular weight organic compound is the least soluble of the model compounds studied; however, the addition of 0.5 $\mathrm{M}$ ammonium sulfate (which is ubiquitous in the atmosphere) allowed for the same $\sim 20 \%$ reduction in surface tension at half the cis-pinonic acid concentration $(0.02 \mathrm{M}$ rather than $0.04 \mathrm{M})$. 
Numerous modeling studies have been performed to estimate the effect of the observed surface tension depression and gradual dissolution of organic compounds. These studies illustrate that the response in $\mathrm{CCN}$ concentrations from the presence of organic surfactants is often important, and strongly depends on the size distribution of chemical composition and aerosol number, and the local dynamical conditions of cloud formation. Nenes et al. [2002] used a numerical cloud parcel model to show that the reduction in surface tension due to organic surfactants can, for polluted aerosol at high updraft velocities, have a greater effect on droplet number than doubling aerosol number. For marine aerosol at low updraft, the enhancement in droplet number from surfactants can be $50 \%$ of the enhancement from doubling aerosol number. Rissman et al. [2004] modified an existing parameterization by Abdul-Razzak et al. [1998, 2000] to explicitly account for the effect of surface active organics on droplet number. Rissman et al. [2004] conclude that the normalized cloud droplet number sensitivity to aerosol organic mass fraction is usually between 10 and $50 \%$ of the sensitivity to updraft velocity, with the strongest relative sensitivity at higher updraft velocity. For marine aerosol, as updraft velocity increases above $\sim 0.4 \mathrm{~m} \mathrm{~s}^{-1}$, the relative sensitivity becomes nearly constant. For continental aerosol, the relative sensitivity can be negative at low updraft velocities, implying that an increase in aerosol organic mass fraction increases $\mathrm{CCN}$ concentration, but decreases the number of cloud droplets (by decreasing the maximum supersaturation). Mircea et al [2002] estimated that including the surface tension effects of water soluble organic compounds may increase the $\mathrm{CCN}$ number concentration by up to $13 \%$ for a marine aerosol, by up to $97 \%$ for a rural aerosol and by up to $110 \%$ for an urban aerosol, under typical atmospheric supersaturations. 
The presence of organic film-forming compounds (FFCs), which form a thin film over a partially deliquesced aerosol particle (with the hydrophobic side of the molecules facing outward and the hydrophilic side facing inward), have the potential to inhibit the rate of droplet growth. The condensation coefficient, which is the probability of a water vapor molecule "sticking" upon collision with an aerosol particle, may be considerably reduced when FFCs are present on the particle surface. A condensation coefficient of 0.045 is widely recognized by the cloud physics community as the typical value for atmospheric droplets (e.g. Feingold and Chuang [2002] used a value of 0.042 to represent typical FFC-free cloud droplets), although the value varies significantly between studies [Mozurkewich, 1986; Pruppacher and Klett, 2000]. Pruppacher and Klett [2000] summarize that an aged atmospheric drop will have a condensation coefficient of $\sim 0.01$ while a clean drop will have a value closer to unity. Two recent studies indicate that the condensation coefficient of pure water is even smaller than previously estimated; Shaw and Lamb [1999] estimate a value of 0.04-0.1 and Li et al [2001] estimate a value of $0.17 \pm 0.03$ at $280 \mathrm{~K}$ and $0.32 \pm 0.04$ at $258 \mathrm{~K}$.

There is evidence for the existence of FFC compounds in ambient aerosol that lower the condensation coefficient to as low as $10^{-5}$ [Chuang, 2003]. This lower condensation coefficient indicates that at least $99.98 \%$ fewer collisions result in "capture" of a water molecule from the gas as compared to an uncoated cloud drop. The chemical composition of FFC-coated particles and the corresponding condensation coefficients are issues that need to be addressed in future studies. In addition, the distribution of FFCs within the aerosol population must be looked at carefully. The modeling study of Feingold and Chuang [2002] shows that when a minor fraction (5-10\% mass) of polluted 
aerosol is composed of FFCs, and the FFC is distributed according to surface area, modified growth kinetics can suppress the number of cloud droplets by as much as $90 \%$. When Nenes et al. [2002] distributed the same organic FFC by aerosol mass, a decrease in the initial rate of condensation led to a large enough increase in cloud parcel supersaturation that the result was an increase (by 50-100\%) in cloud droplet number. For marine aerosols, both studies found that cloud droplet number was modestly affected by the presence of FFCs. Feingold and Chuang [2002] also did simulations in which the FFC was distributed by mass, which resulted in nearly the same droplet number as when FFCs were not present. However, Feingold and Chuang [2002] used a unimodal lognormal size distribution whereas Nenes et al [2002] used a trimodal lognormal distribution. Distributing the FFC by mass reduces the growth of larger aerosol particles, which can increase the cloud supersaturation and allow more of the smaller particles to activate. The greater number of larger aerosol in the Nenes et al [2002] study may have been a significant factor enabling greater droplet activation when the condensation coefficient was decreased to $10^{-5}$.

These and many other studies have shown that considerable variability in cloud droplet number may be induced by different chemical effects, but they do not assess the potential significance of the chemical effects on scales larger than individual updrafts. The current study attempts to address the cloud-system scale by using an inverse modeling approach based on an observational dataset that includes cumuliform and stratiform clouds and CCN originating from both clean and polluted conditions. This unique approach uses empirical correlations of droplet number versus aerosol number and sulfate mass, observed ranges of chemical composition, cloud dynamics and aerosol 
size distribution to constrain the chemical effects on cloud droplet number. We use a numerical adiabatic cloud parcel model with explicit microphysics [Nenes et al., 2001] to determine the minimum updraft velocity required to produce the number of droplets described by the Boucher and Lohmann [1995] and Gultepe and Isaac [1999] correlations. This representative base-case updraft velocity is then used with the parcel model to estimate the sensitivity of cloud droplet number to organic chemical effects. For comparison, cloud droplet number sensitivity to updraft velocity is also evaluated.

\section{Methods}

Not all the factors affecting the number of cloud droplets are available from the published data. To overcome this lack of information, we adopt an inverse modeling analysis to constrain key unresolved parameters. The procedure is illustrated in Figure 1. For a given aerosol number, the Gultepe and Isaac [1999] correlations provide the cloud droplet number, and the Boucher and Lohmann [1995] correlations provide the aerosol sulfate mass. With information about the aerosol size distribution, an updraft velocity can be determined that is consistent with the observations; these conditions are used as a "base-case". Organic mass fraction, condensation coefficient, updraft velocity, and aerosol number concentration are then varied to assess their effects on cloud droplet number. The aerosol physical characteristics (Table 1) and chemical composition (Table 2) used in the analysis are obtained from published literature.

The exact procedure (Figure 1) is as follows: 1) specify the average aerosol physical and chemical characteristic for three typical environments (polluted, continental and marine) based on published observations, 2) determine a likely droplet number 
concentration based on the empirical correlations of Gultepe and Isaac [1999], 3) using the Boucher and Lohmann [1995] correlations, determine a representative sulfate mass concentration that corresponds to the cloud droplet concentration determined from the Gultepe and Isaac [1999] correlations, 4) determine the coarse mode sulfate mass fraction or coarse mode number concentration needed to provide this total sulfate mass, and 5) determine an updraft velocity that can produce the droplet concentration from step 2 using the numerical cloud parcel model of Nenes et al. [2001]. These representative updraft velocities and aerosol characteristics are referred to as the "base-case" values. The sensitivity of cloud droplet number to chemical effects is assessed by introducing a reasonable variability in organic mass fraction and condensation coefficient. The sensitivity of cloud droplet number to updraft velocity is also computed for comparison. When varying the cloud updraft velocity, the organic mass fraction is maintained at the base-case value, with a condensation coefficient of 0.045 . When varying the organic mass fraction, the base-case updraft velocity is maintained, with a condensation coefficient of 0.045 . While varying the condensation coefficient, the base-case updraft velocity and organic mass fraction are assumed.

\section{The Aerosol}

Aerosol are diverse in their size distribution, number concentration and chemical composition, and exhibit significant spatiotemporal variability. As changes in aerosol physical characteristics are known to have a significant effect on the resulting cloud droplet number, the aerosol characteristics used in this analysis must encompass this diversity. 
Regardless of the origin of the air mass, often three distinct modes are observed in the aerosol size distribution (nuclei, accumulation and coarse modes). The nuclei and accumulation modes together represent what are often referred to as "fine particles" (with geometric mean diameters less than $0.1 \mu \mathrm{m})$. Whitby [1978] characterized sulfurcontaining aerosols by averaging multiple size distribution measurements made at several sites over a decade. These measurements were fit to trimodal lognormal distributions, as shown for marine, continental, and polluted aerosol in Table 1.

Fine particle chemical compositions have been analyzed by Heintzenberg [1989], using data from 21 cities in the United States, China, Europe and Japan; 15 non-urban continental sites in Sweden, Brazil, the United States and United Kingdom; and 13 locations in remote marine regions (Table 2). The fine particles mainly consist of sulfate, carbonaceous material (including elemental and organic carbon), ammonia and nitrate. While inorganic compounds are easily resolved by chemical analysis, a substantial portion of organic matter in atmospheric aerosols has remained uncharacterized due to the wide range of carbon numbers, functional groups and solubilities in extraction media [Saxena and Hildemann, 1996]. The organic mass fraction in polluted and continental aerosol often comprises an estimated $20 \%$ of fine particle mass [Heintzenberg, 1989; Ramanathan et al., 2001; Neusü $\beta$ et al., 2002]. However, the organic mass fraction may potentially be as high as $70 \%$ for a highly polluted aerosol [Saxena and Hildemann, 1996]. It is estimated that organic carbon (OC) can represent up to $50 \%$ of the $\mathrm{PM}_{10}$ mass over the continental U.S. [Saxena and Hildemann, 1996; Seinfeld and Pandis, 1998]. Given that the total organic mass can be up to 2.1 times the OC mass for nonurban aerosol [Turpin and Lim, 2001], organic compounds may represent up to $100 \%$ of 
the aerosol mass in continental aerosol. For marine aerosol, the organic mass fraction may be as high as $41-67 \%$ [Heintzenberg, 1989].

\section{Aerosol used in this study}

Three different aerosol (marine, continental and polluted) are represented in this study. The trimodal lognormal size distributions used in this analysis are based on the distributions of Whitby [1978], scaling the modal aerosol number concentrations to be within the range of the Gultepe and Isaac [1999] observations (Table 3). Heintzenberg's [1989] observed sulfate and organic mass fractions represent the fine particle composition for these cases (Table 2). The polluted coarse mode aerosol composition is estimated by averaging mass fraction observations reported by Ramanathan et al. [2001], Neusü $\beta$ et al. [2002] and Finlayson-Pitts and Pitts [1986]. The marine coarse mode aerosol composition estimated by Fitzgerald [1991] is used, and the continental coarse mode composition is assumed to be $90 \%$ insoluble and $10 \%$ ammonium sulfate. We vary the fine particle organic mass fractions from 0 to 0.41 (marine), from 0 to 0.45 (continental) and 0 to 0.61 (polluted), which are below the ranges previously noted. When the organic mass fraction is increased, the sulfate mass fraction remains as specified by Heintzenberg [1989], and the insoluble mass fraction is adjusted. This is an important difference from many studies (e.g. Li et al [1998]), in which highly hygroscopic inorganic salts are replaced with partially soluble organic compounds.

The water-soluble organic component (by a simplification of chemical composition observed in Po Valley, Italy) is assumed to be composed of (by mass) 18\% levoglucosan $\left(\mathrm{C}_{6} \mathrm{H}_{10} \mathrm{O}_{5}\right.$, density $=1600 \mathrm{~kg} \mathrm{~m}^{-3}$, van't Hoff factor $\left.=1\right), 41 \%$ succinic acid 
$\left(\mathrm{C}_{6} \mathrm{O}_{4} \mathrm{H}_{6}\right.$, density $=1572 \mathrm{~kg} \mathrm{~m}^{-3}$, van't Hoff factor $\left.=3\right)$, and $41 \%$ fulvic acid $\left(\mathrm{C}_{33} \mathrm{H}_{32} \mathrm{O}_{19}\right.$, density $=1500 \mathrm{~kg} \mathrm{~m}^{-3}$, van't Hoff factor $=5$ ) [Nenes et al., 2002]. The average solubility is assumed to be $0.02 \mathrm{~kg} / \mathrm{kg} \mathrm{H}_{2} \mathrm{O}$ (or, 0.1 moles $\mathrm{C} \mathrm{L}^{-1}$ ).

\section{Aerosol - Droplet Number Correlations}

The data represented by the Boucher and Lohmann [1995] and Gultepe and Isaac [1999] correlations cover a wide range of conditions of cloud formation. The Boucher and Lohmann [1995] correlations are based on four datasets, which include 85 observations of cloud droplet number and cloud water sulfate within stratiform and cumuliform clouds over North America [Leaitch et al., 1992]; 15 observations of nss sulfate and $\mathrm{CCN}$ active at $0.3 \%$ supersaturation at Cheeka Peak, Washington [Berresheim et al., 1993; Quinn et al., 1993]; 12 observations of dimethylsulfide (DMS), nss sulfate mass, and CCN active over the Northeast Atlantic [Hegg et al., 1993]; and 14 observations of accumulation mode particle concentrations and sulfate mass concentrations over the North Atlantic [Van Dingenen et al., unpublished data].

The Gultepe and Isaac [1999] plots of cloud droplet number concentration versus aerosol number concentration is based on five datasets, which include observations in Syracuse, New York; Ontario (EMEFS I and EMEFS II); Nova Scotia (NARE); Bay of Fundy and central Ontario (RACE). There were more than 10,000 observations collected over a period of eleven years. The cloud types observed were primarily stratus and stratocumulus.

These observations exhibit a high degree of variability. Thus, we do not use the correlations to predict the number of droplets for individual updrafts. Rather, the 
correlations are used to estimate a representative updraft velocity that is required to produce the typical observed droplet concentration for cloud-systems in different environments (represented by average aerosol chemical and physical characteristics, and a representative "base-case" updraft velocity). The Gultepe and Isaac [1999] and Boucher and Lohmann [1995] correlations are currently being used in GCMs, and their inherent variability contributes to the large predictive uncertainty in the models. By evaluating the sensitivities within the context of these correlations, we are providing an assessment within the framework of the current methodology.

\section{The Cloud Parcel Model}

The cloud parcel model [Nenes et al., 2001] captures the explicit aerosol microphysics of cloud droplet formation by diffusional growth. The model simulates the evolution of liquid water cloud droplet distributions in a non-precipitating, adiabatic updraft and has been used in numerous studies, including a successful CCN/Cloud droplet number closure study using in-situ observations from the NASA Crystal-FACE mission [Conant et al, in press]. The model does not include collision-coalescence processes, but rather focuses on cloud droplet activation. The presence of slightly soluble and surfactant substances in CCN is treated explicitly, using the Facchini et al. [1999] correlation to characterize the surface tension of the growing droplets. The model computes the time-dependent particle sizes, water vapor supersaturation, pressure and temperature. The initial parcel conditions assumed are a relative humidity of $98 \%$, temperature of $284.2 \mathrm{~K}$, and pressure of $939 \mathrm{mb}$. The aerosol is not initially in equilibrium with the environment. The updraft is assumed constant, since we are only 
interested in the cloud drop activation process, which generally occurs on the order of seconds; the buoyancy of the cloud parcel does not change significantly within this time. The number of droplets is computed by finding the $\mathrm{CCN}$ of highest critical supersaturation that activates (i.e. with a diameter larger than its critical diameter, evaluated at cloud top). Particles larger than this characteristic CCN are considered droplets. This definition of cloud droplets includes large CCN, which have not attained their critical diameter but are as large as activated drops $(\sim 1 \mu \mathrm{m})$, and does not include CCN that deactivate and become interstitial aerosol.

A film-breaking model is used to evaluate the effect of Film-Forming Compounds (FFCs). The model assumes that the presence of FFCs on the droplet surface decreases the condensation coefficient to $10^{-5}$. The FFC is distributed among the aerosol by mass, which is appropriate for primary sources, whereas a surface area weighted distribution would be more appropriate for secondary organics that have entered the particles via condensation [Feingold and Chuang, 2002]. As the droplet grows, the film thickness decreases. At the point when a monolayer of FFC ( $0.5 \mathrm{~nm}$ thick $)$ is achieved, the film breaks and the condensation coefficient immediately increases to 0.045 . The FFC mass fraction is assumed equal to the base-case organic mass fraction, only for determining how long it takes the film to break. When FFCs are not present, a constant condensation coefficient of 0.045 is assumed, uniform for all particles. In addition, a simulation is performed with a constant condensation coefficient of 0.005 , to represent the maximum potential effect of FFCs. A thermal accommodation coefficient of unity is assumed [Shaw and Lamb, 1999]. It should be noted that the structure and evolution of films, in 
addition to the size-resolved chemical composition of the films themselves, are so uncertain that the mechanism of the film-breaking model is highly speculative.

\section{Empirical Correlations and Model Setup}

The Boucher and Lohmann [1995] and Gultepe and Isaac [1999] relationships correlate cloud droplet number concentration with different aerosol characteristics. Employing both relationships consistently limits two of three key aerosol-cloud interaction parameters (sulfate mass, aerosol and droplet number). By specifying a total aerosol number concentration $\left(N_{a p}\right.$ ) for each environment (Table 3), cloud droplet number concentration $\left(N_{d}\right)$ is calculated according to the empirical best fit relationships of Gultepe and Isaac [1999], as shown below.

$$
N_{d}= \begin{cases}-595+298 \log \left(N_{a p}\right) & \text { Continental and Polluted } \\ -273+162 \log \left(N_{a p}\right) & \text { Marine }\end{cases}
$$

The Gultepe and Isaac [1999] correlation (Equation (1a)) can be applied for $N_{a p}$ up to $1,000 \mathrm{~cm}^{-3}$ and $1,500 \mathrm{~cm}^{-3}$ for the continental and polluted environments, respectively, since this is the range of the observations. Because of this, the continental and polluted fine particle number concentrations from Whitby [1978] are reduced so that the total aerosol number concentrations are $1,000 \mathrm{~cm}^{-3}$ and $1,500 \mathrm{~cm}^{-3}$, respectively, while the mean diameter and mean dispersion are kept constant. Reducing the particle number concentration can be justified physically as dilution of an urban plume or vertical 
mixing of a continental air mass. Thus, the polluted case should be thought of as "diluted polluted" and the continental as "clean continental".

The cloud droplet number concentration, computed from Equation 1, is introduced into the Boucher and Lohmann [1995] correlation to obtain the total aerosol sulfate mass concentration $\left(m_{S O 4}\right)$ :

$$
\begin{array}{ll}
m_{\text {SO } 4}=10^{\left\{\frac{\log \left(N_{d}\right)-2.21}{0.41}\right\}} & \text { Average } \\
m_{S O 4}=10^{\left\{\frac{\log \left(N_{d}\right)-2.06}{0.48}\right\}} & \text { Maritime }
\end{array}
$$

Table 3 shows the base-case droplet number $\left(N_{d}\right)$ and total aerosol sulfate mass $\left(m_{S O 4}\right)$ as constrained by these correlations.

Aerosol mass is often dominated by the larger particles, while number is dominated by smaller particles. Because of this, we need to be careful in how the sulfate is distributed throughout the size distribution. The sulfate mass determined by the Boucher and Lohmann [1995] correlation, $m_{S O 4}$, is equal to the sum of the sulfate mass within each lognormal mode. The sulfate mass concentration of each lognormal mode $\left(m_{S O 4 i}\right)$ is calculated according to Equations (3)-(5).

$$
m_{S O 4 i}=\varepsilon_{S O 4 i} \rho_{a p i} V_{i}
$$


where,

$$
\rho_{a p i}=\frac{1}{\frac{\varepsilon_{o i}}{\rho_{o i}}+\frac{\varepsilon_{s i}}{\rho_{s i}}+\frac{\varepsilon_{i n s i}}{\rho_{i n s i}}}
$$

The subscript $s$ denotes properties of the soluble component, $o$ stands for the organic component (which is slightly soluble), ins stands for the insoluble component, and the trailing subscript $i$ indicates the modes (Nuclei, Accumulation and Coarse). In the absence of other soluble compounds, the sulfate mass fraction $\left(\varepsilon_{S O 4 i}\right)$ is related to the soluble mass fraction $\left(\varepsilon_{s i}\right)$ by the ratio of their molecular weights $\left(M_{S O 4} / M_{s}\right)$, where $M_{s}$ is the molecular weight of ammonium sulfate. For the marine coarse aerosol, the addition of $\mathrm{NaCl}$ yields: $\varepsilon_{s i}=\varepsilon_{\left(\mathrm{NH}_{4}\right)_{2} \mathrm{SO}_{4} i}+\varepsilon_{\mathrm{NaCli}}$ where $\varepsilon_{\left(\mathrm{NH}_{4}\right)_{2} \mathrm{SO}_{4} i}=\varepsilon_{\mathrm{SO}_{4} i}\left(\frac{M_{\left(\mathrm{NH}_{4}\right)_{2} \mathrm{SO}_{4}}}{M_{\mathrm{SO} 4}}\right)$.

The volume concentration $\left(V_{i}\right)$ is calculated from the number concentration $\left(N_{i}\right)$, geometric mean diameter $\left(\bar{D}_{g i}\right)$ and geometric standard deviation $\left(\sigma_{g i}\right)$ for each mode, according to the following equation.

$$
V_{i}=N_{i}\left(\frac{\pi}{6}\right) \exp \left(3 \ln \bar{D}_{g i}+\frac{9}{2} \ln ^{2} \sigma_{g i}\right)
$$

Given that a variety of combinations of $m_{\mathrm{SO} 4 i}$ can give $m_{\mathrm{SO} 4}$, we consider values that are consistent with observations. In this study, we set the fine particle mass fractions to the values reported by Heintzenberg [1989] (Table 2), and then compute the coarse mode sulfate mass fraction from the constraint $\Sigma m_{S O 4 i}=m_{S O 4}$. If the computed coarse 
mode sulfate mass fraction is not within observed values, then we assume instead an observed coarse mode sulfate fraction and adjust the coarse mode number concentration so that $\Sigma m_{S O 4 i}=m_{S O 4}$.

Adjustment of the chemical composition or number concentration of the coarse mode can be justified in two ways. First, coarse mode measurements are often the least certain of the three modes, due to limitations in the instrumentation [Baron and Willeke, 2001]. Second, the contribution of the coarse mode particles to cloud droplet number is negligible, on the order of $1-10 \mathrm{~cm}^{-3}$. Therefore, given that the coarse particle sulfate mass fraction can strongly influence sulfate mass burden, it is preferable to first assign the sulfate mass for the fine particles and then attribute the remaining sulfate mass, given by the Boucher and Lohmann [1995] correlations, to the coarse particles.

Using the procedure outlined above, coarse mode sulfate mass fractions are calculated for the marine and polluted aerosol (keeping coarse mode number concentrations constant). The calculated coarse mode sulfate mass fraction for the polluted aerosol is 0.11 , midway between the observed range, 0.02 and 0.25 [Ramanathan et al., 2001; Neusüß et al., 2002; Finlayson-Pitts and Pitts, 1986]. Coarse mode particles in the marine boundary layer are primarily composed of sea salt, with much smaller amounts of nitrates and mineral dust [Fitzgerald, 1991]. Sea salt consists of $\sim 7.68 \%$ (by mass) sulfate [Seinfeld and Pandis, 1998], so that, in the absence of other mechanisms, the coarse mode mass fraction of sulfate should be less than 0.08 for the marine aerosol. Our analysis yields a coarse mode sulfate mass fraction of 0.01 , which is slightly lower than expected. 
The continental aerosol distribution used lacks sufficient coarse mode particles to yield a $m_{S O 4}$ consistent with the Boucher and Lohmann [1995] correlation. Increasing the coarse mode number concentration from $0.72 \mathrm{~cm}^{-3}$ to $4.1 \mathrm{~cm}^{-3}$ satisfies the constraint $\Sigma m_{S O 4 i}=m_{S O 4}$. This change has a negligible impact on $\mathrm{CCN}$ and droplet number concentrations.

\section{Results}

\section{Base-case Updraft Velocity}

Ensuring that the aerosol chemistry and size distribution are consistent with observations is a necessary but not sufficient condition for the plausibility of our analysis. The base-case updraft velocity must also be consistent with observations; otherwise, the sensitivities calculated may not be representative of the ambient atmosphere, as they have been shown to be strong functions of updraft velocity and chemical composition [e.g., Rissman et al., 2004]. The base-case updraft velocity is inferred, rather than prescribed, because updraft is highly uncertain; it is both difficult to measure and highly variable.

Coalescence and entrainment may have in reality affected observations of droplet number, although these processes are not explicitly addressed within the parcel model. However, these processes can only reduce droplet number. Thus, the calculated basecase updraft velocity actually represents the minimum cooling rate required to produce the number of cloud droplets that are predicted by the empirical correlations. Where entrainment does exist, this means that a greater updraft velocity is required to produce the observed number of droplets. A higher updraft is expected to enhance the relative sensitivity of cloud droplet number to surface tension effects [Rissman et al, 2004]. 
The base-case updraft velocity is determined iteratively. Updraft velocity is varied until cloud droplet number calculated from the cloud parcel model matches the Gultepe and Isaac [1999] and Boucher and Lohmann [1995] correlations. The resulting base-case updraft velocities are $\sim 0.7-1.5 \mathrm{~m} \mathrm{~s}^{-1}$ for the continental case and $\sim 2-3.5 \mathrm{~m} \mathrm{~s}^{-1}$ for the polluted case, which are within the expected range (e.g. $0-1 \mathrm{~m} \mathrm{~s}^{-1}$ for stratiform and $\sim 1-17 \mathrm{~m} \mathrm{~s}^{-1}$ for continental cumulus clouds [Seinfeld and Pandis, 1998]). Mason [1971] found that updrafts in non-precipitating continental cumulus clouds are typically no greater than 5-7 $\mathrm{m} \mathrm{s}^{-1}$. The maximum parcel supersaturations for the continental and polluted base-cases are $0.7-0.8 \%$ and $1.2-1.4 \%$, respectively. Supersaturations in the ambient atmosphere are usually less than $1 \%$ and almost never exceed $2 \%$ [Seinfeld and Pandis, 1998]. Although the base-case updraft velocities and maximum supersaturations are higher than average values measured in situ, this is expected. Within a single cloud, the higher end of the updraft velocity spectrum is expected to control the total number of cloud droplets formed. Thus, when a single updraft is used to represent the production of cloud droplets, its intensity is expected to be larger than average, but still within the observed range. Thus, the base-case aerosol size distribution and chemical composition are reasonable representations of the ambient aerosol for the continental and polluted cases.

Surface tension depression from the presence of the organics is not considered for the base-case calculations; if surfactants were considered, the base-case updraft velocities would be cut in half and the maximum supersaturations would be reduced to $0.4-0.5 \%$ and $0.8-0.9 \%$, for the continental and polluted cases, respectively. 
If the condensation coefficient were increased from 0.045 to 1.0 , the maximum supersaturation for the base-case does not change significantly, but the base-case updraft velocity doubles for both the continental and polluted cases. With a higher condensation coefficient, an increased rate of condensation in the initial stages of cloud formation leads to a lower cloud supersaturation, and thus a lower cloud droplet number. Since the droplet number is constrained, the required updraft velocity must increase in order to provide the same driving force for condensational growth.

The updraft velocity for the marine environment is expected to be lower than updraft velocities over continents. However, using the Whitby [1978] distribution, the base-case updraft velocity for the marine case is $\sim 13 \mathrm{~m} \mathrm{~s}^{-1}$ (neglecting surface tension effects), which is apparently greatly overestimated. If we use a different size distribution from Heintzenberg [2000] and Jaenicke [1993] (Table 1), the base-case updraft velocity is reduced to $0.1-0.35 \mathrm{~m} \mathrm{~s}^{-1}$. While the total number of aerosol particles remains nearly the same as from Whitby [1978] (within 2\%), this alternative particle size distribution has a larger proportion of particles in the accumulation mode, where the majority of $\mathrm{CCN}$ are found. The maximum parcel supersaturation for this new base-case is less than $0.5 \%$, whereas using the Whitby [1978] remote marine distribution the maximum supersaturation was $>5 \%$, which is not realistic for the atmosphere. Thus, we use the Heintzenberg [2000]/Jaenicke [1993] aerosol size distribution for the marine case in our analysis.

Heintzenberg [2000] grouped a total of 64 independent observations of marine fine aerosol size distributions from all over the world according to latitude (Table 1). Interestingly, the Whitby [1978] size distribution most closely approximates the latitude 
range $60-75^{\circ} \mathrm{S}$, in terms of the proportion of aerosol in the nuclei and accumulation modes. This latitude range is very remote, and in fact, Whitby [1978] actually describe the observations as representative of a "remote marine" environment. By comparison, the 24 independent observations of fine aerosol size distribution that are listed within the latitude range $15-60^{\circ} \mathrm{N}$ by Heintzenberg [2000] are likely influenced by anthropogenic activities. Since, the Boucher and Lohmann [1995] and Gultepe and Isaac [1999] observations are from the northern hemisphere, we take an average of the size distribution parameters in the latitude range $15-60^{\circ} \mathrm{N}$ from Heintzenberg [2000] to represent the fine marine aerosol in our analysis. The Jaenicke [1993] distribution is used to represent sea salt aerosol, which closely resembles the Whitby [1978] marine coarse mode aerosol distribution. With this new marine size distribution, the calculated coarse mode sulfate mass fraction increases from 0.01 to 0.05 , which is closer to the expected value of $\sim 0.08$.

\section{Sensitivity of Droplet Number to Updraft Velocity}

The observations covered by the correlations include both stratiform and cumuliform datasets. For this reason, we consider a range of updrafts between 0.1 and 5 $\mathrm{m} \mathrm{s}^{-1}$ for the continental and polluted cases, and between 0.05 and $3 \mathrm{~m} \mathrm{~s}^{-1}$ for the marine case, to cover the expected variability of droplet number from dynamical effects in both cloud types [Mason, 1971].

For the updraft velocity sensitivity analysis, the cloud parcel model is run twice (first at a high updraft velocity and then at a low updraft velocity) for each of the three aerosol number concentrations $(1.0,0.75$ and 0.50 times the base-case aerosol number 
concentration) and for each of the three environments (marine, continental and polluted). In these simulations, the organic component of the aerosol is not considered a surfactant, meaning that the surface tension remains constant as the droplet grows.

For the marine base-case (using the Heintzenberg [2000]/Jaenicke [1993] distribution), cloud droplet number varies from 91 to $336 \mathrm{~cm}^{-3}$ as a result of changes in updraft velocity (Figure 2). The maximum parcel supersaturation corresponding to the 3 $\mathrm{m} \mathrm{s}^{-1}$ updraft velocity for this case is $1.25-1.5 \%$, which is on the high end of observations. This indicates that either the high updraft is very unlikely, or it indicates the presence of an aerosol with a chemical composition and/or size distribution that differs significantly from the average. Increasing the condensation coefficient to 1.0 decreases the maximum supersaturation for $3 \mathrm{~m} \mathrm{~s}^{-1}$ updrafts to $0.9-1.1 \%$. However, the number of droplets also decreases by $11-18 \%$.

For the continental base-case, cloud droplet number varies from $112-510 \mathrm{~cm}^{-3}$ (Figure 3), and for the polluted base-case, cloud droplet number varies from $91-495 \mathrm{~cm}^{-3}$ as a result of changes in updraft velocity (Figure 4). For the continental case, this variability $\left(\sim 400 \mathrm{~cm}^{-3}\right)$ encompasses a majority of the scatter in the observations. However, for the polluted case, a significant fraction of the observations appear to be unexplained by the very large updraft variability.

The maximum parcel supersaturations within $5 \mathrm{~m} \mathrm{~s}^{-1}$ updrafts are 1.6-1.9\% and 1.7-2.0\% for the continental and polluted cases, respectively. Changing the condensation coefficient to 1.0 changes the maximum supersaturations to $1-1.4 \%$ and $1.2-1.5 \%$. However, the number of droplets decreases with this higher condensation coefficient, by $18-19 \%$ and $20-27 \%$, respectively. Including the surface tension effect would also 
slightly decrease the maximum supersaturation within $5 \mathrm{~m} \mathrm{~s}^{-1}$ updrafts, but would result in an increase in cloud droplet number by up to $39 \%$.

\section{Sensitivity of Droplet Number to Chemical Effects}

The cloud parcel model is run twice (high and low organic mass fractions specified in Table 4) for each of the three number concentrations and for each of the three aerosol types, to determine the sensitivity of cloud droplet number to surfactants. Only the fine particle organic mass fractions (which contribute the most to the $\mathrm{CCN}$ ) are manipulated. These simulations utilize a constant condensation coefficient of 0.045 under the base-case updraft conditions.

Two additional simulations are performed to address the sensitivity of droplet number to a delayed condensational growth rate that may result from the presence of FFCs on the droplet surface. Surface tension effects are neglected for these simulations. First, the condensation coefficient is decreased by approximately one order of magnitude (from 0.045 to 0.005 ). Then a non-constant condensation coefficient is assessed using a film-breaking model, for which the lowered condensation coefficient $\left(10^{-5}\right)$ changes to 0.045 when the film breaks. Three different aerosol number concentrations and three different aerosol types are assessed, at the base-case updraft velocity and base-case organic mass fraction.

For the marine base-case, increasing the organic mass fraction from 0 to 0.41 increases the number of cloud droplets from 137 to $166 \mathrm{~cm}^{-3}$ (Figure 2). This increase $\left(\sim 30 \mathrm{~cm}^{-3}\right)$ is mainly due to the effect of surface tension depression by the organic species, but is also influenced by the replacement of insoluble compounds with slightly 
soluble compounds. For the constant 0.005 condensation coefficient, the number of cloud droplets for the marine base-case increases further to $190 \mathrm{~cm}^{-3}$. Using the filmbreaking model yields a droplet number of $173 \mathrm{~cm}^{-3}$. Thus, the overall sensitivity of droplet number to chemical effects for the marine base-case is $\sim 50 \mathrm{~cm}^{-3}$. This is $\sim 20 \%$ of the cloud droplet sensitivity from updraft variability.

As a result of surface tension effects, increasing the organic mass fraction increases the number of droplets from 270 to $399 \mathrm{~cm}^{-3}$ (continental base-case), and from 302 to $591 \mathrm{~cm}^{-3}$ (polluted base-case). The constant 0.005 condensation coefficient simulation increases the number of droplets further to $462 \mathrm{~cm}^{-3}$ and $695 \mathrm{~cm}^{-3}$, for the continental and polluted base-cases, respectively. Thus, the cloud droplet number sensitivity to surfactants is $32-36 \%$ (continental) and 79-96\% (polluted) of the sensitivity induced by updraft variability. However, it is important to note that the number of droplets resulting from surface tension effects can be much greater than the droplet number resulting from high updraft velocity. In other words, surface tension effects shifts the variability to higher droplet concentrations. This is typically the case for the polluted aerosol.

Surface tension effects increased the number of cloud droplets by $9-35 \%$ (marine), 30-33\% (continental) and 54-68\% (polluted) from the base-case. Mircea et al [2002] also found that the change in droplet number resulting from replacing insoluble compounds with surfactants was greater for the urban aerosol (110\% increase in droplet number from the base-case) and rural aerosol (97\% increase) than for marine aerosol (13\% increase). 
The constant 0.005 condensation coefficient simulations produce the greatest number of cloud droplets resulting from chemical effects. One of the interesting results is that the highest sensitivity of cloud droplet number to condensation coefficient appears to be at or near typical observations of cloud droplet condensation coefficient (i.e. 0.045). Decreasing the condensation coefficient further (below $10^{-3}$ ) has an almost negligible effect on droplet number, as most of the aerosol particles have already activated by this point. As mentioned previously, condensation coefficients on the order of $10^{-5}$ have been suggested for atmospheric aerosol influenced by FFCs. When the film-breaking model is introduced, the effect on droplet number is less pronounced than with a constant condensation coefficient; using the film-breaking model produces $91 \%$ (for the marine base-case), $76 \%$ (continental) and $62 \%$ (polluted) of the droplet number resulting from the constant condensation coefficient simulation. Nevertheless, for the polluted case, the increase in droplet number using the film-breaking model is nearly equivalent to the effect from a $5 \mathrm{~m} \mathrm{~s}^{-1}$ updraft.

\section{Chemical and Dynamical Effects for Variable Aerosol Number}

It is instructive to examine the variability from chemical and dynamical effects for other values of the aerosol number concentration. The striking feature for all three aerosol is the remarkable robustness of the variability; chemical effects remain significant, even when decreasing the aerosol number concentration by $25 \%$ and $50 \%$. Since the Gultepe and Isaac [1999] observations of aerosol concentration only go up to $1,000 \mathrm{~cm}^{-3}$ (for continental aerosol) and $1,500 \mathrm{~cm}^{-3}$ (for the polluted aerosol), the correlations cannot be used to extrapolate the base-case updraft velocity, and we cannot 
assess the sensitivity for higher concentration plumes, although there are indications that the sensitivity may change under such conditions [Rissman et al, 2004].

In general, the relative sensitivity of cloud droplet number to surfactants increases as the aerosol number concentration decreases. This is most important for the marine case (Figure 2) while it appears negligible for the continental and polluted cases (Figures 3 and 4). For the marine case, the sensitivity of droplet number to surfactants increases from $15 \%$ to $35 \%$ when the aerosol number concentration is reduced by $50 \%$ from the base-case. The marine base-case updraft velocities are on the most sensitive region of the relative organic surfactant sensitivity plot of Rissman et al [2004]. At the lower aerosol number concentration, a higher base-case updraft is required. As updraft velocity increases $\left(0.1 \mathrm{~m} \mathrm{~s}^{-1}\right.$ for the base-case $N_{a p}, 0.16 \mathrm{~m} \mathrm{~s}^{-1}$ with $75 \% N_{a p}$ and $0.35 \mathrm{~m} \mathrm{~s}^{-1}$ with $50 \% N_{a p}$ ) surface tension effects have a larger relative effect on droplet number, as expected from the results of Rissman et al [2004]. Conversely, the continental base-case updraft velocities are within a stable regime on the Rissman et al [2004] relative sensitivity plot, and an increase in the base-case updraft velocities causes only a slight increase in the relative sensitivity of droplet number to surfactants.

\section{Implications for the Aerosol Indirect Effect}

The first indirect effect is related to changes in cloud reflectivity, which can be characterized fairly well with two of the following three parameters: cloud liquid water content, effective radius and droplet number. By assuming a constant liquid water content $\left(q_{c}\right)$, a change in droplet number $\left(N_{d}\right)$ can be roughly related to a change in 
cloud reflectivity $\left(R_{c}\right)$. The approximation, $\Delta R_{c} \sim 0.075 \Delta \ln \left(N_{d}\right)$, is valid within $10 \%$ for an initial cloud reflectivity between 0.28 and 0.72 [Seinfeld and Pandis, 1998]. We assume an initial $R_{c}$ of 0.5 and plot the average percent change in $R_{c}$ resulting from changes in cloud droplet number from updraft variability and chemical effects (Figure 5). This rough approximation shows that chemical effects, which includes both surface tension effects and changes in the condensation coefficient, may enhance cloud reflectivity by $4-10 \%$, with respect to the base-case cloud droplet number. Comparatively, variations in updraft velocity are expected to enhance cloud reflectivity by $2-12 \%$.

The second indirect effect, which is related to cloud lifetime, is an even greater challenge to quantify. We look at the rate of autoconversion, $Q_{\text {aut }}$, to represent the second indirect effect, since autoconversion is the rate of initial generation of rain/drizzle from cloud water, which has direct implications for cloud lifetime. The Khairoutdinov and Kogan [2000] parameterization describes $Q_{a u t}$ as a function of droplet number and cloud liquid water content, $Q_{a u t}=1350 q_{c}^{2.47} N_{d}^{-1.79}$. Assuming constant liquid water content, the increase in droplet number resulting from chemical effects suggests that $Q_{a u t}$ may decrease by $34-63 \%$. This is due to the smaller sizes of the droplets, which have smaller settling velocities, thereby decreasing their rate of collision. For comparison, a high updraft velocity may decrease $Q_{a u t}$ by $19-76 \%$.

\section{Conclusions}


This study assesses the variability in cloud droplet number that may result from the effect of organic species on surface tension and from the effect of film forming compounds on the water vapor condensation coefficient. The cloud droplet number variability is compared to the variability caused by uncertainties in updraft velocity. An inverse-modeling approach is employed for this task. Using a detailed numerical cloud parcel model, observed aerosol characteristics and correlations of cloud droplet vs. sulfate and cloud droplet vs. aerosol number, a most probable size distribution and updraft velocity for polluted and clean conditions is obtained. The variation in cloud droplet number from expected variations in aerosol chemistry and updraft velocity is then compared to the observed cloud droplet number scatter in the empirical aerosol sulfatecloud droplet number correlation.

Three important results come out of this study. First, chemical effects can potentially have a significant effect on cloud droplet number concentration for conditions ranging from marine to polluted in the regions surrounding the North American continent and Atlantic ocean. Chemical effects may account for an average of 28\% (marine), $49 \%$ (continental) and greater than $100 \%$ (polluted) of the variability in cloud droplet number, as compared to the variability from updraft velocity. This underlines the importance of including chemical effects within GCM assessments of the aerosol indirect effect, and challenges the common belief that the variability seen in empirical aerosol-cloud droplet number relationships is primarily from the highly variable cloud dynamics.

Another important finding is that surface tension effects may enhance the sensitivity of droplet number to variations in updraft velocity. Thus, the microphysical characteristics of clouds originating from organic $\mathrm{CCN}$ are likely more sensitive to the 
shape of the updraft velocity spectrum, than for clouds composed of purely inorganic CCN. Including surface tension effects increases the number of cloud droplets formed in $5 \mathrm{~m} \mathrm{~s}^{-1}$ updrafts by $55-63 \%$ for the polluted case and $30-39 \%$ for the continental case, and increases the number of cloud droplets formed in $3 \mathrm{~m} \mathrm{~s}^{-1}$ updrafts by $14-16 \%$ for the marine case. Thus, surface tension effects could help to explain the high end of the measured cloud droplet number variability.

The other significant finding is that the relative effect of organic species on cloud droplet number appears relatively insensitive to the aerosol number concentration for a wide range of aerosol and updraft conditions typically found in GCM simulations. This suggests that the relative importance of chemical effects on cloud droplet number may not be masked by fluctuations in aerosol number concentration expected on the spatial scale of a typical GCM grid cell. 


\section{Acknowledgements}

This work was supported by a National Science Foundation CAREER award and by the NASA Earth Observing System-Interdisciplinary Science program (NASA EOSIDS). We also acknowledge the support of a Georgia Institute of Technology Presidential Fellowship and a National Center for Atmospheric Research Advanced Study Program Fellowship. 


\section{References}

Abdul-Razzak, H., S.J. Ghan, and C. Rivera-Carpio, A parameterization of aerosol activation: 1. Single aerosol type. J. Geophys. Res., 103, 6123-6131, 1998.

Abdul-Razzak, H. and S.J. Ghan, A parameterization of aerosol activation: 2. Multiple aerosol types. J. Geophys. Res., 105, 6837-6844, 2000.

Baron, P.A. and K. Willeke (eds.), Aerosol Measurement: Principles, Techniques, and Applications, $2^{\text {nd }}$ ed., Wiley-Interscience, Canada, 2001.

Berresheim, H., F.L. Eisele, D.J. Tanner, L.M. McInnes, D.C. Ramsey-Bell and D.S. Covert, Atmospheric Sulfur Chemistry and Cloud Condensation Nuclei (CCN) Concentrations over the Northeastern Pacific Coase. J. Geophys. Res., 98, 12701-12711, 1993.

Boucher, O. and U. Lohmann, The Sulfate-CCN-Cloud Albedo Effect: A Sensitivity Study with Two General Circulation Models. Tellus, Series B, 47, 291-300, 1995.

Charlson, R.J., J.H. Seinfeld, A. Nenes, M. Kulmala, A. Laaksonen, and M.C. Macchini, Reshaping the Theory of Cloud Formation. Science, 292, 2025-2026, 2001.

Charlson, R.J., J.E. Lovelock, M.O. Andreae, S.G. Warren, Nature, 326, 655, 1987.

Chuang, P.Y. Measurement of the Timescale of Hygroscopic Growth for Atmospheric Aerosols. J. Geophys. Res., 108 (D9), 4282, doi:10.1029/2002JD002757, 2003.

Conant, W.C., T.M. VanReken, T.A. Rissman, V. Varutbangkul, H.H. Jonsson, A. Nenes, J.L. Jimenez, A.E. Delia, R. Bahreini, G.C. Roberts, R.C. Flagan and J.G. Seinfeld, Aerosol-Cloud Drop Concentration Closure in Warm Cumulus, in press. 
Facchini, M.C., S. Decesari, M. Mircea, S. Fuzzi and G. Loglio, Surface Tension of Atmospheric Wet Aerosol and Cloud/For Droplets in Relation to their Organic Carbon Content and Chemical Composition. Atmos. Environ., 34, 4853-4857, 2000.

Facchini, M.C., M. Mircea, S. Fuzzl, and R.J. Charlson, Cloud Albedo Enhancement by Surface-Active Organic Solutes in Growing Droplets. Nature, 401, 257-259, 1999.

Feingold, G. and P.Y. Chuang, Analysis of the Influence of Film-Forming Compounds on droplet Growth: Implications for Cloud Microphysical Processes and Climate. $J$. Atmos. Sci., 59, 2006-2018, 2002.

Finlayson-Pitts, B.J., and J. N. Pitts, Atmospheric Chemistry: Fundamentals and Experimental Techniques, John Wiley, New York, USA, 1986.

Fitzgerald, J.W. Marine Aerosols: A Review. Atmos. Environ., 25A, 533-545, 1991.

Gultepe, I., and G.A. Isaac, Scale Effects on Averaging of Cloud Droplet and Aerosol Number Concentrations: Observations and Models. J. Climate, 12, 1268-1279, 1999.

Hegg, D.A., R.J. Ferek and P.V. Hobbs, Light Scattering and Cloud Condensation Nucleus Activity of Sulfate Aerosol Measured over the Northeast Atlantic Ocean. $J$. Geophys. Res., 98, 14887-14894, 1993.

Heintzenberg, J., D.C. Covert and R. Van Dingenen, Size Distribution and Chemical Composition of Marine Aerosols: A Compilation and Review. Tellus, Series B, 52, 1104$1122,2000$.

Heintzenberg, J. Fine Particles in the Global Troposphere: A Review. Tellus, Series B, 41, 149-160, 1989. 
Houghton, J.T., Y. Ding, D.J. Griggs, M. Noguer, P.J. van der Linden, X. Dai, K. Maskell, and C.A. Johnson (eds.) Climate Change 2001: The Scientific Basis.

Contribution of Working Group I to the Third Assessment Report of the Intergovernmental Panel on Climate Change. Cambridge University Press, UK, 2001.

Jones, A., D.L. Roberts and A. Slingo, A Climate Model Study of the Indirect Radiative Forcing by Anthropogenic Sulphate Aerosols. Nature, 370, 450-453, 1994.

Khairoutdinov, M. and Y. Kogan, A New Cloud Physics Parameterization in a LargeEddy Simulation Model of Marine Stratocumulus. Mon. Weather Rev., 128 (1), 229-243, 2000.

Leaitch, W.R., G.A. Isaac, J.W. Strapp, C.M. Banic, and H.A. Wiebe, The Relationship Between Cloud Droplet Number Concentrations and Anthropogenic Pollution:

Observations and Climatic Implications. J. Geophys. Res., 97, 2463-2474, 1992.

Li, Y.Q., P. Davidovits, Q. Shi, J.T. Jayne, C.E. Kolb and D.R. Worsnop, Mass and Thermal Accommodation Coefficients of $\mathrm{H}_{2} \mathrm{O}(\mathrm{g})$ on Liquid Water as a Function of Temperature. J. Phys. Chem., 105 (47), 10627-10634, 2001.

Li, Z., A.L. Williams, and M.J. Rood, Influence of Soluble Surfactant Properties on the Activation of Aerosol Particles Containing Inorganic Solute. J. Atmos. Sci., 55 (10), 1859-1866, 1998.

Mason, B.J., The Physics of Clouds. Oxford Press, Oxford, 1971.

Mircea, M., M.C. Facchini, S. Decesari, S. Fuzzi and R.J. Charlson, The Influence of the Organic Aerosol Component on CCN Supersaturation Spectra for Different Aerosol Types. Tellus, Series B, 54, 74-81, 2002. 
Mozurkewich, M. Aerosol Growth and the Condensation Coefficient for Water: A

Review. Aerosol Sci. Technol., 5, 223-236, 1986.

Nenes, A. and Seinfeld, J.H. Parameterization of cloud droplet formation in global climate models J. Geophys. Res., 108 (D7), 4415, doi: 10.1029/2002JD002911, 2003.

Nenes, A. R.J. Charlson, M.C. Facchini, M. Kulmala, A. Laaksonen, and J.H. Seinfeld, Can Chemical Effects on Cloud Droplet Number Rival the First Indirect Effect?, Geophys. Res. Lett, 24 (17), 1848, doi: 10.1029/2002GL015295, 2002.

Nenes., A., S. Ghan, H. Abdul-Razzak, P.Y. Chuang, and J.H. Seinfeld, Kinetic Limitations on Cloud Droplet Formation and Impact on Cloud Albedo, Tellus, Series B, 53, 133-149, 2001.

Neusüß, C., H. Wex, W. Birmili, A. Wiedensohler, C. Koziar, B. Busch, E. Brüggemann, T. Gnauk, M. Ebert, and D.S. Covert. Characterization and Parameterization of Atmospheric Particle Number-, Mass-, and Chemical-Size Distributions in Central Europe During LACE 98 and MINT. J. Geophys. Res., 107 (D21), 8127, doi:10.1029/2001JD000514, 2002.

Novakov, T., C. Rivera-Carpio, J.E. Penner and C.F. Rogers, The Effect of Anthropogenic Sulfate Aerosols on Marine Cloud Droplet Concentrations, Tellus, Series $B, 46,132-141,1994$.

Pruppacher, H.R. and J.D. Klett, Microphysics of Clouds and Precipitation. Kluwer Academic Publishers, Dordrecht, Netherlands, 2000.

Quinn, P.K., D.S. Covert, T.S. Bates, V.N. Kapustin, D.C. Ramsey-Bell, and L.M. McInnes, Dimethylsulfide/Cloud Condensation Nuclei/Climate System: Relevant SizeResolved Measurements of the Chemical and Physical Properties of the Atmospheric Aerosol Particles. J. Geophys. Res., 98, 10411-10427, 1993. 
Ramanathan, V. et al., Indian Ocean Experiment: An Integrated Analysis of the Climate Forcing and Effects of the Great Indo-Asian Haze. J. Geophys. Res., 106, 28371-28398, 2001.

Rissman, T., A. Nenes, and J.H. Seinfeld, Chemical amplification (or dampening) of the Twomey effect: Conditions derived from droplet activation theory, J. Atmos. Sci., 61 (8), 919-930, 2004.

Saxena, P. and L.M. Hildemann, Water-Soluble Organics in Atmospheric Particles: A Critical Review of the Literature and Application of Thermodynamics to Identify Candidate Compounds. J. Atmos. Chem., 24, 57-109, 1996.

Seinfeld, J. and S. Pandis, Atmospheric Chemistry and Physics: from Air Pollution to Climate Change, John Wiley, New York, 1998.

Shaw R.A. and D. Lamb, Experimental Determination of the Thermal Accommodation and Condensation Coefficients of Water, J. Chem. Phys., 111 (23), 1999.

Shulman, M., M. Jacobson, R. Charlson, R. Synovec, and T. Young, Dissolution Behavior and Surface Tension Effects of Organic Compounds in Nucleating Cloud Droplets. Geophys. Res. Lett., 23, 277-280, 1996.

Turpin, B.J. and H.J. Lim, Species Contributions to PM2.5 Mass Concentrations: Revisiting Common Assumptions for Estimating Organic Mass. Aerosol Sci. Technol., 35, 602-610, 2001.

Twomey, S. Pollution and the Planetary Albedo. Atmos. Environ., 8, 1251-1256, 1974.

Whitby, K.T. and G.M. Sverdrup (1978). California Aerosols: Their Physical and Chemical Characteristics, within The Character and Origins of Smog Aerosols: A Digest 
of Results from the California Aerosol Characterization Experiment (ACHEX). John Wiley, New York, 477-517, 1980.

Whitby, K.T. The Physical Characteristics of Sulfur Aerosols. Atmos. Environ., 12, 135159, 1978. 


\section{Figure Captions}

Figure 1. Flow diagram illustrating the "inverse modeling" analysis methodology used for determining cloud droplet number concentration sensitivities. Steps 1-4 (in circles) involve manipulation of observational data, while the remaining steps (in diamonds) employ the cloud parcel model.

Figure 2. Marine cloud droplet number sensitivity to updraft velocity and chemical effects (using the Heintzenberg [2000]/Jaenicke [1993] size distribution). Maritime observations, average correlation (-...-) and maritime correlation (---) are from Boucher and Lohmann [1995]. Marine case cloud parcel model results for high updraft velocity (grey squares), low updraft velocity (white squares), high organic mass fraction (grey circles), low organic mass fraction (white circles), constant condensation coefficient (0.005, grey triangles) and changing condensation coefficient $\left(10^{-5}\right.$ to 0.045 , white triangles) are overlaid on the observational data. The values of organic mass fraction and updraft velocity for each simulation point is given in Table 4. The condensation coefficient is 0.045 , except where otherwise specified. The inset shows the full range of the observations, on a log-log scale.

Figure 3. Same as Figure 2, but for continental aerosol with the average correlation and including all observations from Boucher and Lohmann [1995].

Figure 4. Same as Figure 3, but for polluted aerosol.

Figure 5. Estimated percent change in cloud reflectivity resulting from increases in droplet number from chemical effects and updraft variability, assuming a constant liquid water content and using a parameterization from Seinfeld and Pandis [1998]. An initial cloud reflectivity of 0.5 is assumed. 


\section{Tables}

\begin{tabular}{lcccccccccc}
\hline \multicolumn{1}{c}{ Aerosol } & \multicolumn{3}{c}{ Nuclei Mode } & \multicolumn{4}{c}{ Accumulation Mode } & \multicolumn{3}{c}{ Coarse Mode } \\
\multicolumn{1}{c}{ Type } & $\bar{D}_{g 1}$ & $\sigma_{g 1}$ & $N_{1}$ & $\bar{D}_{g 2}$ & $\sigma_{g 2}$ & $N_{2}$ & $\bar{D}_{g 3}$ & $\sigma_{g 3}$ & $N_{3}$ \\
\hline Remote Marine & 0.01 & 1.6 & 340 & 0.071 & 2.0 & 60 & 0.62 & 2.7 & 3.1 \\
*Latitudes $60-75^{\circ} \mathrm{S}$ & 0.018 & 1.4 & 310 & 0.075 & 1.6 & 70 & 0.58 & 2.49 & 3.1 \\
*Latitudes $15-60^{\circ} \mathrm{N}$ & 0.020 & 1.47 & 230 & 0.092 & 1.47 & 176.7 & 0.58 & 2.49 & 3.1 \\
Clean Continental & 0.016 & 1.6 & 1000 & 0.067 & 2.1 & 800 & 0.93 & 2.2 & 0.72 \\
Polluted & 0.014 & 1.8 & 106000 & 0.054 & 2.16 & 32000 & 0.86 & 2.21 & 5.4
\end{tabular}

Table 1. Average modal size distribution parameters $\left(\bar{D}_{g i}\right.$ in $\mu \mathrm{m}, N_{i}$ in $\left.\mathrm{cm}^{-3}\right)$ from

Whitby [1978]. *Average fine marine parameters over the latitude range from

Heintzenberg [2000] and coarse mode parameters from Jaenicke [1993]. 


\begin{tabular}{lrrrrrrr}
\hline & \multicolumn{3}{c}{ Fine } & \multicolumn{5}{c}{ Coarse } \\
Aerosol type & $\mathcal{E}_{S O 4}$ & $\mathcal{E}_{o}$ & $\mathcal{E}_{\text {ins }}$ & $\mathcal{E}_{S O 4}$ & $\mathcal{E}_{\mathrm{NaCl}}$ & $\mathcal{E}_{o}$ & $\mathcal{E}_{\text {ins }}$ \\
\hline Marine & 0.22 & 0.11 & 0.67 & 0.05 & 0.93 & - & 0.05 \\
Clean Continental & 0.37 & 0.24 & 0.39 & 0.07 & - & - & 0.9 \\
Diluted Polluted & 0.28 & 0.31 & 0.41 & 0.11 & - & 0.2 & 0.644
\end{tabular}

Table 2. Modal base-case chemical composition for each aerosol type used in this study. The fine particle $\left(\bar{D}_{g i}<0.1 \mu \mathrm{m}\right)$ mass fractions are obtained from Heintzenberg [1989]. Coarse mode sulfate mass fractions are calculated using the procedure outlined in the text. The other coarse mode mass fractions are estimated from [Fitzgerald, 1991; Ramanathan et al., 2001; Neusüß et al., 2002; Finlayson-Pitts and Pitts, 1986]. 


\begin{tabular}{|c|c|c|c|c|c|c|}
\hline \multirow[b]{2}{*}{ Aerosol Type } & \multicolumn{4}{|c|}{ Modal Number Concentration $\left(\mathrm{cm}^{-3}\right)$} & \multicolumn{2}{|c|}{$\begin{array}{c}\text { Parameters } \\
\text { Constrained by } \\
\text { Droplet Correlations }\end{array}$} \\
\hline & Nuclei & Accumulation & Coarse & Total $\left(N_{a p}\right)$ & $N_{d} *$ & $m_{S O 4} * *$ \\
\hline Marine & 230 & 177 & 3.1 & 410 & 150 & 1.75 \\
\hline Clean Continental & 555 & 444 & 4.1 & 1003 & 299 & 4.46 \\
\hline Diluted Polluted & 1152 & 348 & 5.4 & 1505 & 352 & 6.62 \\
\hline
\end{tabular}

Table 3. Base-case modal aerosol number concentrations $\left(N_{i}\left[\mathrm{~cm}^{-3}\right]\right)$ as obtained from the procedure outlined in the text. The other modal size distribution parameters are given in Table 1. Base-case droplet number $\left(N_{d}\left[\mathrm{~cm}^{-3}\right]\right)$ and total aerosol sulfate mass $\left(m_{S O 4}\right.$, $\left.\left[\mu \mathrm{g} \mathrm{m}^{-3}\right]\right)$ as constrained by the Gultepe and Isaac [1999]* and Boucher and Lohmann [1995]** correlations. 


\begin{tabular}{lcccccc}
\hline \multirow{2}{*}{ Aerosol type } & \multicolumn{2}{c}{ Updraft Velocity $\left(\mathbf{m ~ s}^{-\mathbf{1}}\right)$} & \multicolumn{3}{c}{$\begin{array}{c}\text { Fine Particle Organic } \\
\text { Mass Fraction }\end{array}$} \\
& Base & Lower & Upper & Base & Lower & Upper \\
\hline Marine & $0.1,0.16,0.35$ & 0.05 & 3 & 0.11 & 0 & 0.41 \\
Clean Continental & $0.7,1.0,1.5$ & 0.1 & 5 & 0.24 & 0 & 0.45 \\
Diluted Polluted & $2.0,3.0,3.5$ & 0.1 & 5 & 0.31 & 0 & 0.61
\end{tabular}

Table 4. Base-case, lower and upper limit values for updraft velocity and fine particle organic mass fractions used for assessing the sensitivity to dynamical and chemical effects, respectively. The range of base-case updraft velocities for each aerosol type is for each of the three different aerosol number concentrations $(100 \%, 75 \%$ and $50 \%$ of the base-case $N_{a p}$ given in Table 3). The base-case fine particle organic mass fraction is from Heintzenberg [1989] and the upper limit in organic mass fraction is estimated from Seinfeld and Pandis [1998]. 
Figures

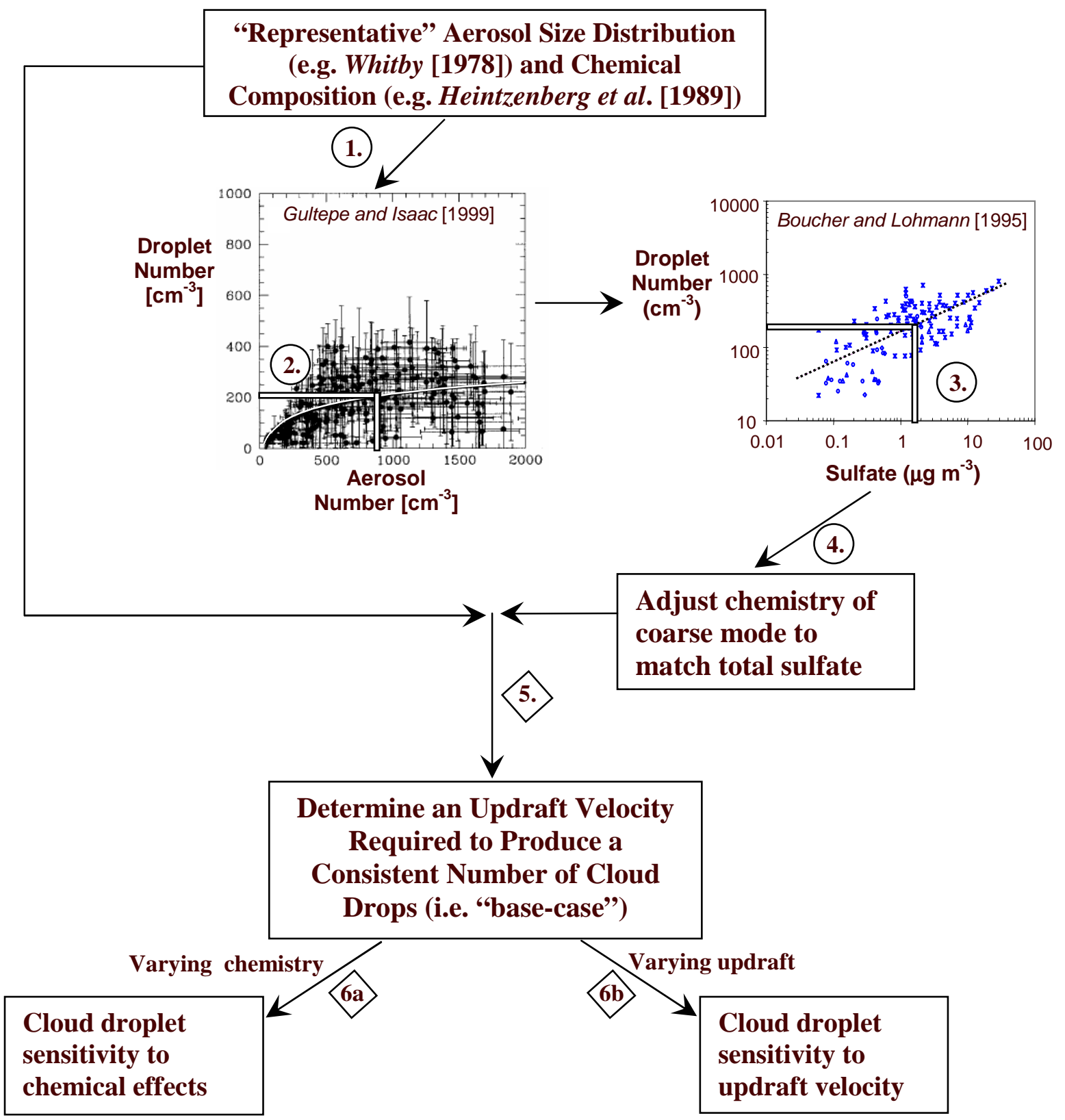

Figure 1. 


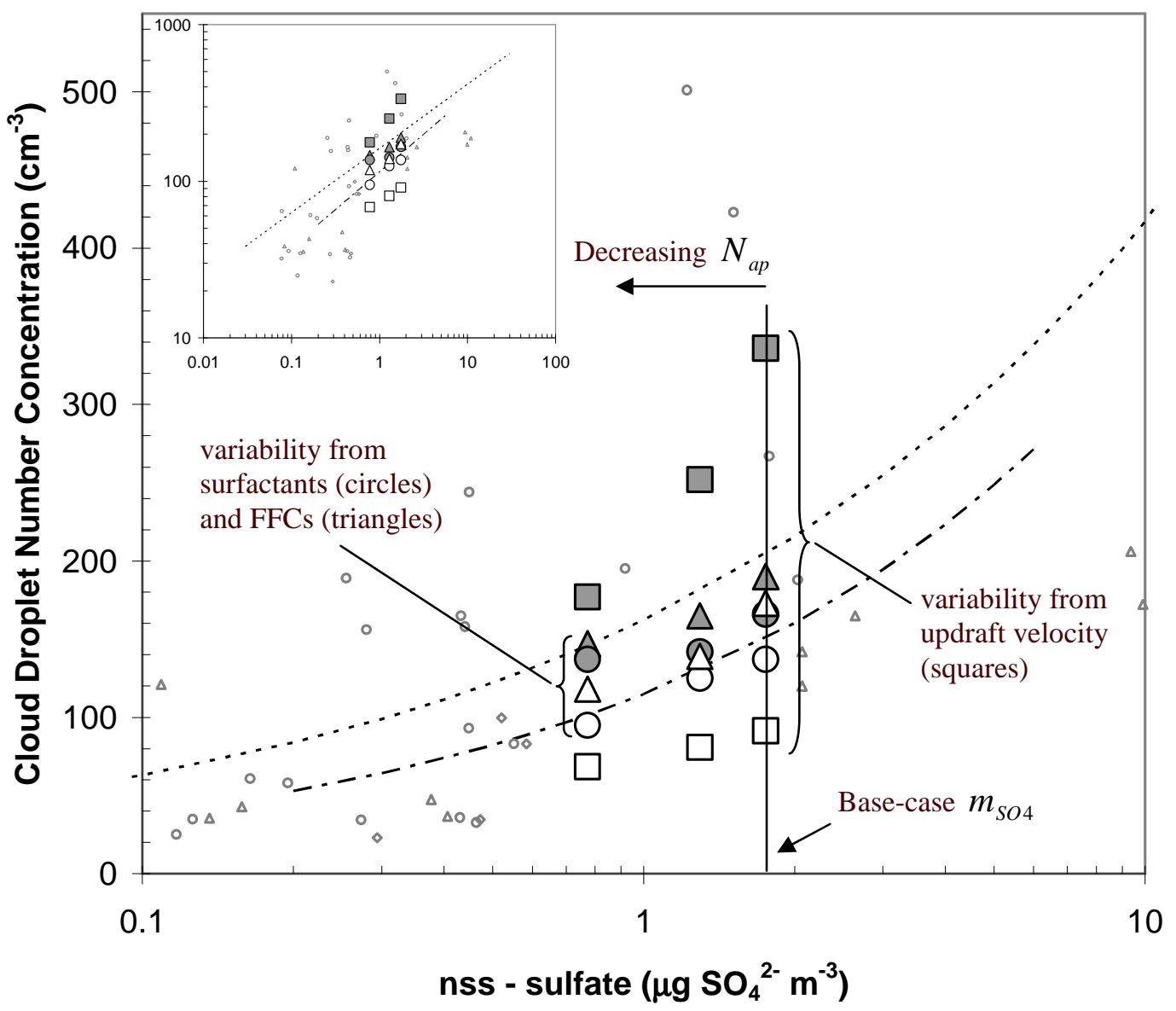

Figure 2. 


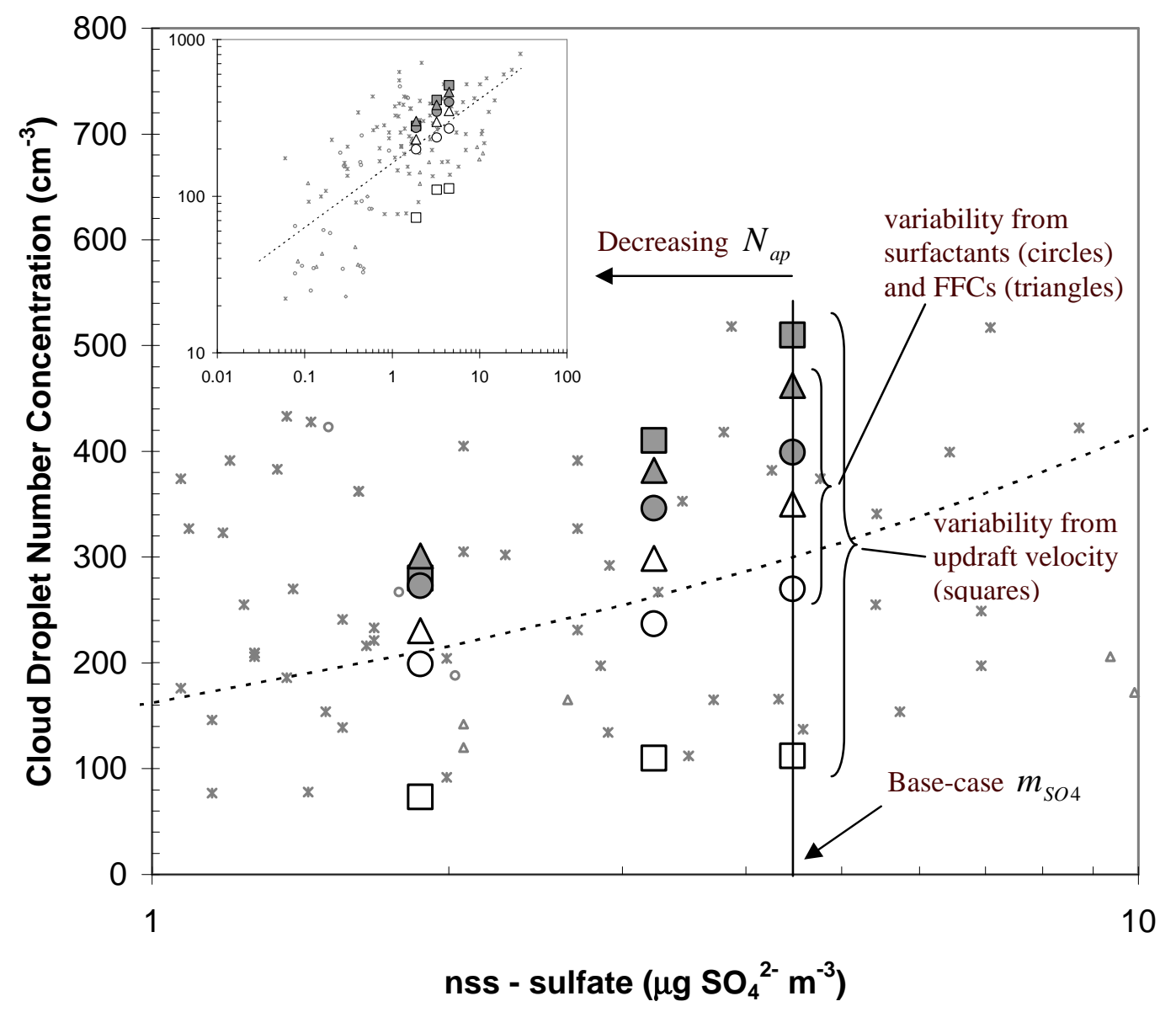

Figure 3. 


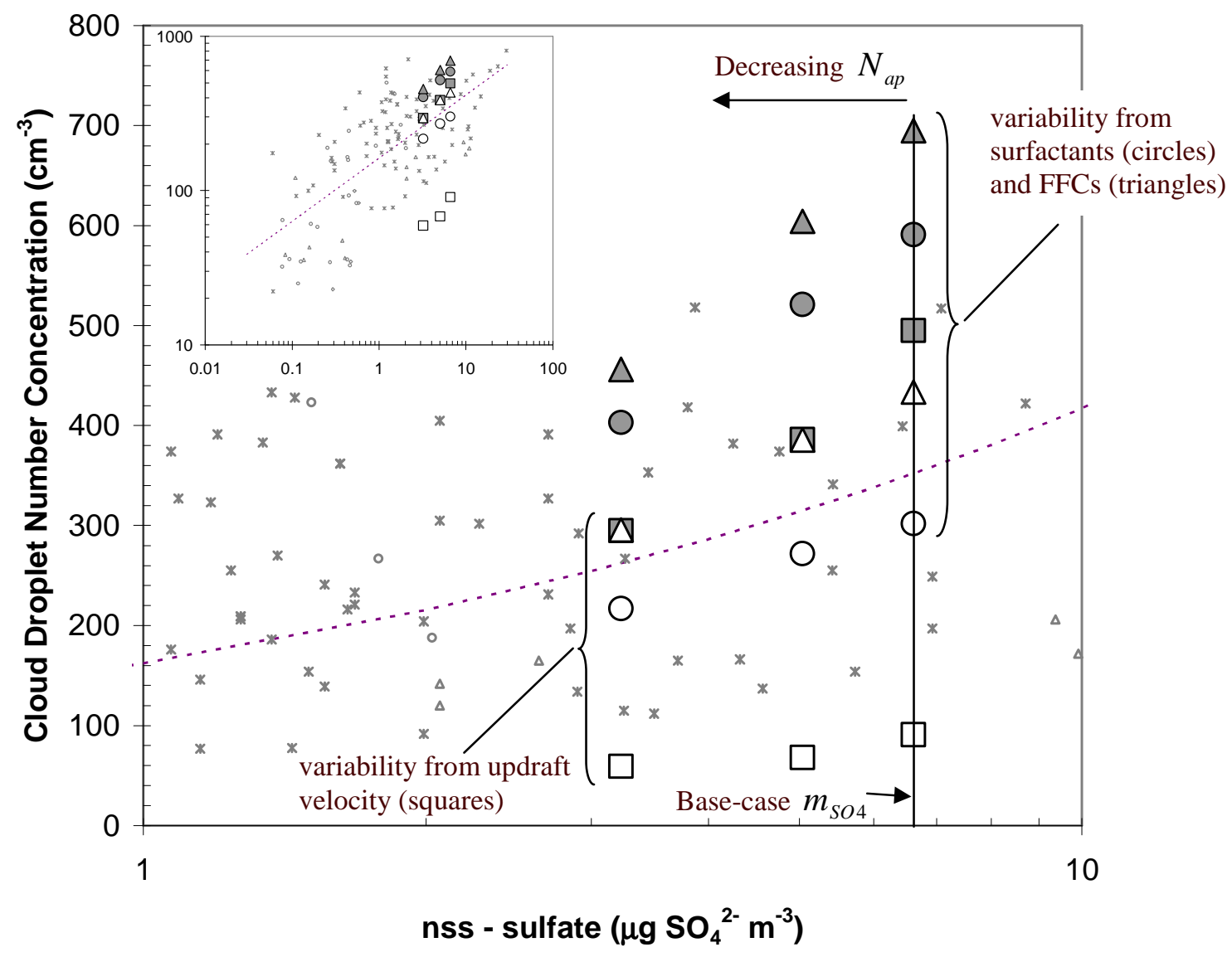

Figure 4. 


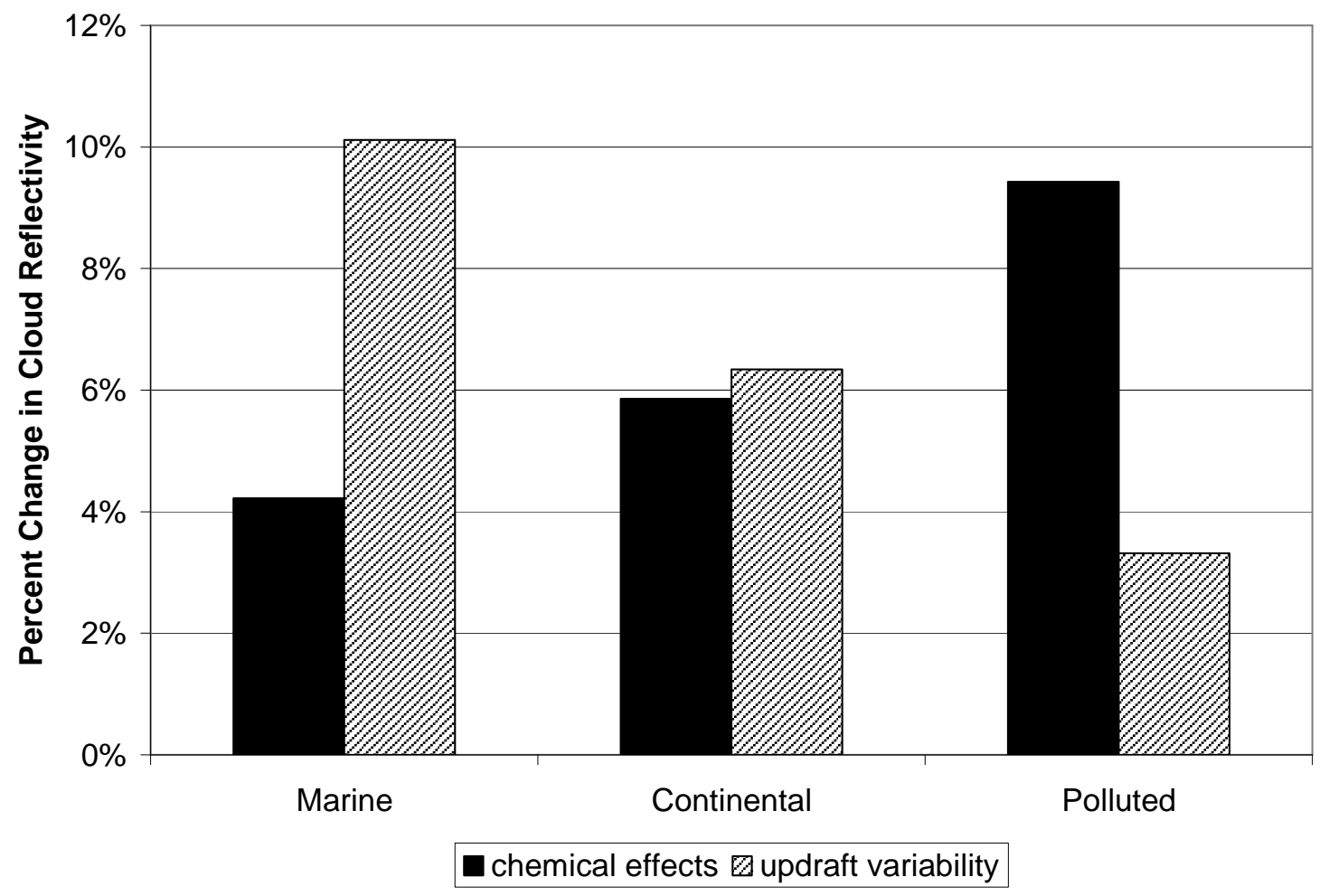

Figure 5. 